\title{
PREPORUKE 2015 - MEĐUNARODNI NAUČNI KONSENZUS O KARDIOPULMONALNOJ REANIMACIJI
}

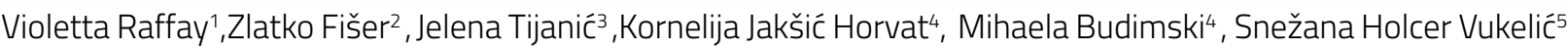

\section{Sažetak}

Međunarodni naučni konsenzus Internacionalnog odbora za Resuscitaciju (ILCOR, International Liaison Committee on Resuscitation, www.ilcor.org) uključuje predstavnike iz American Heart Association (AHA), European Resuscitation Council (Europski Resuscitacioni Savet ERC), Heart and Stroke Foundation of Canada (HSFC), Australian and New Zealand Committee on Resuscitation (ANZCOR), Resuscitation Council of Southern Africa (RCSA), Inter-American Heart Foundation (IAHF) i Resuscitation Council of Asia (RCA). Od 2000. godine istraživači ILCOR ocenjuju resuscitacionu nauku u petogodišnjim ciklusima. Najnoviji međunarodni konsenzus, konferencija održana je u Dallasu u februaru 2015. godine i objavljeni zaključci i preporuke iz ovog saopštenja čine osnovu ovih Preporuka ERC 2015.

Osim šest ILCOR radnih grupa: osnovna životna podrška (BLS); napredna podrška života (ALS); akutni koronarni sindromi (ACS); pedijatrijska podrška života (PLS); neonatalna podrška života (NLS) edukacija, implementacija i trening (EIT); iz 2010. godine, formirana je i Radna grupa za prvu pomoć.

Kao i 2010. godine pripremljen je dokument o konfliktu interesa. Za svaku temu su pozvana najmanje dva stručna recezenta da daju nezavisne procene. Njihov rad je podržan od strane novog i jedinstvenog online sistema SEERS (Scientific Evidence Eval-uation and Review System), koji je razvijen od strane ILCOR. Za procenu kvaliteta dokaza i snage preporuka, ILCOR je usvojio metodologiju GRADE (ocenjivanje preporuka, procena, razvoj i evaluacija). Na ILCOR 2015 konsenzus konferenciji je učestvovalo 232 učesnika koji predstavljaju 39 zemalja; 64\% učesnika je došao van SAD. To učestvovanje je obezbedilo da ova konačna objava preporuka predstavlja stvarni međunarodni konsenzus proces. Tokom tri godine pre konferencije, 250 dokaza

\section{USTANOVA}

Resuscitacioni Savet Srbije 2Zavod za hitnu medicinsku pomoć Novi Sad ${ }^{3}$ Zavod za hitnu medicinsku pomoć Kragujevac

4Dom Zdravlja Subotica

${ }^{5}$ Dom Zdravlja Sombor

\section{AUTOR ZA} KORESPODENCIUU.

Violetta Raffay

Rasuscitacioni savet Srbije

president@resuscitatio.org.rs su pregledali recenzenti iz 39 zemalja, hiljadu relevantnih, publikacija na temu169 specifičnih pitanja, svaki u standardnom PICO formatu (stanovništvo, intervencija, upoređivanje, ishod). Svaka naučna izjava sadrži ekspertsku interpretaciju svih relevantnih podataka na određenu temu i relevantna ILCOR radna grupa dodaje konsenzus nacrta tretmana za preporuku. Konačni tekst naučnih izjava i preporuka za lečenje je završen nakon daljnjeg pregleda od strane organizacije ILCOR članova i uredništva i publikovan u Resuscitation i Circulation kao Naučni konsenzus 2015. preporučenih postupaka (Consensus on Science and Treatment Recommendations-CoSTR). Organizacija članova koju čini ILCOR će objaviti prepouke koje su u skladu s ovim CoSTR dokumentom, ali će takođe razmotriti geografske, ekonomske i sistemske razlike u praksi, dostupnost medicinskim proizvodima i lekovima.

Koenraad G. Monsieurs, Jerry P. Nolan, Leo L. Bossaert, Robert Greif, Ian K. Maconochie, Nikolaos I. Nikolaou, Gavin D. Perkins, Jasmeet Soar, Anatolij Truhlár, Jonathan Wyllie, David A. Zideman, u ime grupe autora ERC Preporuke 2015.

Gamal Eldin Abbas Khalifa, Annette Alfonzo,Hans-Richard Arntz, Helen Askitopoulou, Abdelouahab Bellou, Farzin Beygui, Dominique Biarent, Robert Bingham, Joost JLM Bierens,Bernd W Böttiger, Leo L Bossaert, Guttorm Bratteb $\varnothing$, Hermann Brugger, Jos Bruinenberg, Alain Cariou, Pierre Carli, Pascal Cassan, Maaret Castrén, AthanasiosF Chalkias,Patricia Conaghan, Charles D. Deakin, Emmy DJ De Buck, Joel Dunning, Wiebe De Vries, Thomas R Evans,Christoph Eich, Jan-Thorsten Gräsner, Robert Greif, Christina M Hafner, Anthony J Handley, Kirstie L Haywood, Silvija Hunyadi-Antičević, Rudolph W. Koster, Anne Lippert, David J Lockey, Andrew S Lockey Jesús López-HerceCarsten Lott, Ian K MaconochieSpyros D. Mentzelopoulos, Daniel Meyran, Koenraad G. Monsieurs, Nikolaos I Nikolaou, Jerry P Nolan,Theresa Olasveengen Peter
KLUČNE REČls

vanbolnički srčani zastoj, kardiopulmonalna reanimacija, svedok
DATUM PRIJEMA RADA

10. oktobar 2015.

DaTUM PRIHUATANJA RADA

20. oktobar 2015.

datum ObjayluUanua

10. februar 2016 
Paal, Tommaso Pellis, Gavin D Perkins, Thomas Rajka, Violetta I Raffay, Giuseppe Ristagno, Antonio Rodríguez-Núñez, Charles Christoph Roehr, Mario Rüdiger, Claudio Sandroni, Susanne Schunder-Tatzber, Eunice M Singletary, Markus B. Skrifvars Gary B Smith, Michael A Smyth, Jasmeet Soar, Karl-Christian Thies, Daniele Trevisanuto, Anatolij Truhlár, Philippe G Vandekerckhove, Patrick Van de Voorde, Kjetil Sunde, Berndt Urlesberger, Volker Wenzel, Jonathan Wyllie,Theodoros T Xanthos, David A Zideman.

Ovaj rezime ukazuje na najvažnije promene u sprovođenju mera resuscitacije kod dece i odraslih a u odnosu na Preporuke 2010. Detaljan vodič za svaki od preostalih deset poglavlja, se objavljuje u sklopu izdanja časopisa Resuscitation a prevod na srpski jezik u časopisu Journal Resuscitation Balcanika.

\section{poclavla preporuka 2015.}

\section{Sažetak}

2. Osnovne mere podrške životu odraslih i upotreba spoljašnjeg automatskog defibrilatora'

3. Napredne mere podrške životu odraslih ${ }^{2}$

4. Srčani zastoj u posebnim okolnostima ${ }^{3}$

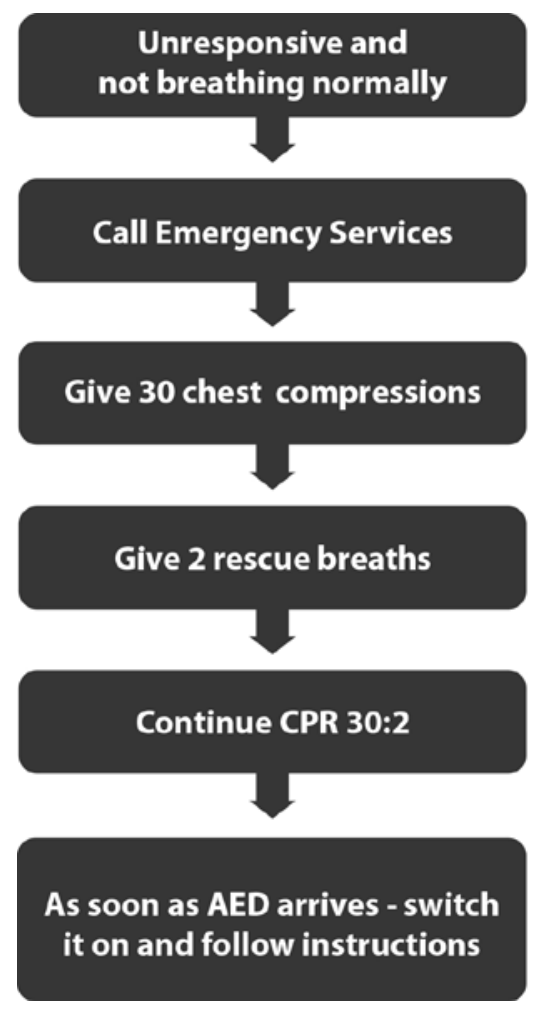

Fig. 1. BLS novi algoritam

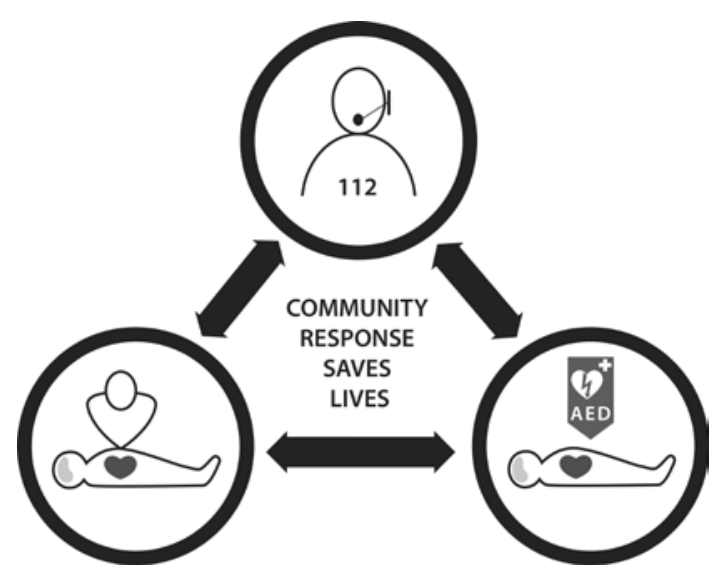

Fig.2. Interakcija između dispečera, očevidca koji započinje KPR i upotrebe AED

5. Post resuscitaciona nega ${ }^{4}$

6. Mere životne podrške dece ${ }^{5}$

7. Mere životne podrške novorođenčadi ${ }^{6}$

8. Akutni koronarni sindromi ${ }^{7}$

9. Prva pomoć ${ }^{8}$

10. Principi edukacije u resuscitaciji ${ }^{9}$

11. Etika i donošenje odluka o prestanku resuscitacije ${ }^{10}$

\section{Osnoune mere žiuotne podrš- ke odraslih i upotreba spoljašnjth automatskih defibrilatora (AED)}

- ERC Preporuke 2015 ističu značaj interakcije između dispečera hitne medicinske pomoći, lica koja se zateknu na mestu zadesa i započinju KPR odnosno pravovremene upotrebe automatskih spoljašnjih defibrilatora. Efikasna koordinacija i zajedničko delovanje dipečera i spasilaca mogu dovesti do poboljšanja preživljavanja kod vanbolničkog srčanog zastoja. ${ }^{11,12}$

- Dispečer hitne medicinske pomoći dobija važnu ulogu u ranom prepoznavanju srčanog zastoja, telefonskom vođenju kardio pulmonalne resuscitacije (KPR ) i davanju informacija o lokaciji najbližeg AED-a. U slučaju srčanog zastoja svi spasilaci, bilo da su posebno edukovani ili bez prethodne edukacije za primenu mera KPR, započinju kompresije grudnog koša.

ERC preporučuje da spasilac treba brzo da proceni stanje unesrećenog kod iznenadnog kolapsa, da proveri stanje svesti i disanje te da neodložno aktivira Službu hitne medicinske pomoći (SHMP).

Osoba koja nije posebno edukovana a očevidac je srčanog zastoja nakon utvrđivanja da unesrećeni ne reaguje, hitno aktivira SHMP i treba da sledi instrukcije dispečera. Poziv hitnoj medicinskoj pomoći treba uputiti bez napuštanja unesrećenog.

Obuka medicinskih dispečera u SHMP usmerava se 
ka poštovanju utvrđenih protokola za prijem poziva. Protokoli imaju za cilj da osoba koja prima poziv, dobije sve potrebne informacije na osnovu kojih može da prepozna pacijenata u verovatnom srčanom zastoju, osobe koje ne reaguju i ne dišu (ili abnormalno dišu). ${ }^{13,}$ $14,15,16$

- Kod osoba bez svesti i disanja, neposredno posle srčanog zastoja, prestaje protok krvi prema mozgu. To može dovesti do pojave grčeva, koji liče na epileptični napad. Očevici i dispečeri hitne medicinske pomoći treba da posumnjaju na pojavu srčanog zastoja kod svih pacijenata sa krizom svesti praćenu grčevima koji podsećaju na epilepileptični napad.

Edukovani spasilac treba da kombinuje kompresije grudnog koša sa ventilacijom. Ne postoji dovoljno dokaza kojima se može potvrditi jednaka uspešnost KPR koja se vrši primenom „samo” kompresija grudnog koša u odnosu na rezultate primene standardnih mera KPR, masaža i ventilacija zajedno. 17, 18, 19

- Visoko kvalitetna KPR osnova je za uspeh mera resuscitacije. Preporuke o dubini i brzini kompresija nisu promenjene. Spoljašnje kompresije grudnog koša vrše se odgovarajućom dubinom (od najmanje 5 $\mathrm{cm}$, a ne više od $6 \mathrm{~cm}$ kod prosečene odrasle osobe) a sa učestalošću 100-120 u minuti. Preporučuje se relaksacija, vraćanje u početni položaj grudnog koša posle svake kompresije, sa minimalizacijom pauza pri masaži. Kada spasilac primenjuje mere veštačkog disanja, tada udisaj treba da traje približno 1 sekundu, a volumen udisaja da bude dovoljan da se grudni koš vidljivo odigne. Odnos kompresija i ventilacija iznosi 30:2. Trajanje prekida kompresija grudnog koša ne treba da bude duže od 10 sekundi. ${ }^{20}$

- Isporuka DC šoka 3-5 minuta od nastanka kolapsa pri srčanom zastoju dovodi do stope preživljavanja srčanog zastoja od 50-70\%. Rana defibrilacija postiže se i primenom javno dostupnih automatskih spoljašnjih defibrilatora. ${ }^{21,22}$

- Mere KPR za odrasle mogu da se bezbedno koriste kod zbrinjavanja dece, koja su bez svesti i ne dišu normalno. Kompresije grudnog koša kod dece treba do jedne trećine AP prečnika grudnog koša (to za malo dete iznosi $4 \mathrm{~cm}$, a za veće dete oko $5 \mathrm{~cm}$ ). ${ }^{23}$

- Začepljenje disajnog puta stranim telom koje dovodi do ozbiljnih teškoća pri disanju je životno ugrožavajuća situacija. Prve mere pomoći sastoje se iz udara između plećki a posle gubitka svesti pritisaka na epigastrijum. Nakon prestanka disanja i gubitka svesti potrebno je odmah započeti KPR. ${ }^{24,25}$

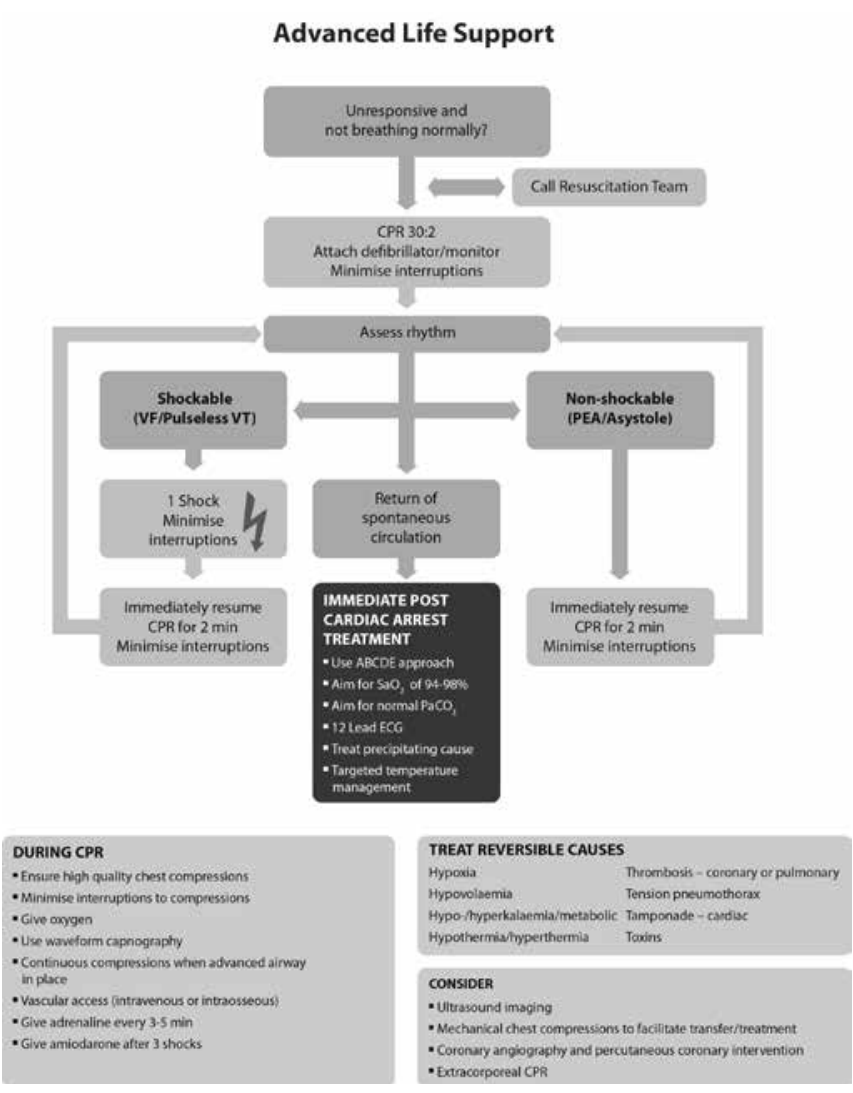

Fig. 3.ALS algoritam

\section{Napredna žfuotna podršlka odraslifh (ALS)}

Preporuke 2015 za napredne mere životne podrške odraslih nisu doživele velike izmene u odnosu na preporuke 2010. Preporuke ukazuju da samo celovito primenjene mere i postupci koje oni sadrže mogu dovesti do poboljšanja krajnjeg ishoda zbrinjavanja srčanog zastoja i preživljavanje pacijenata. 27, 28, 29, 30

Ključne poruke Preporuka su:

-Potrebno je nastaviti sa razvojem bolničkih sistema za brzo reagovanje, prepoznavanje pacijenata sa rizikom, i aktiviranje posebno osposobljenih timova pre nastanka srčanog zastoja kod životno ugroženog pacijenta. Naglasak je na prevenciji srčanog zastoja u bolničkim ustanovama. ${ }^{31}$

- Naglašena važnost visoko kvalitetnih kompresija grudnog koša i minimalizacije prekida kompresija tokom bilo koje ALS intervencije. Kompresije se prekidaju samo pri pokušaju defibrilacije, prekid tom prilikom treba minimalizovati, a ne duže od 5 sekundi. ${ }^{32}$

- Preporuke posebno insistiraju na strategiji defibrilacije sa primenom samolepljivih elektroda, ciljje da se smanji pre šok pauza i vreme prekida kompresija tokom defibrilacije. Znamo da se ponegde još uvek koriste defibrilatori sa papučicama i to treba napustiti. 
- Preporuke ukazuju na značaj monitoringa vitalnih parametara tokom primene naprednih mera podrške životu. Posebno se naglašava značaj primene talasne forme kapnografije za potvrdu pravilnog položaja endotrahealnog tubusa. Kapnografija je korisna za potvrdu kvaliteta KPR i kao rani znak pojave spontane cirkulacije (ROSC). ${ }^{33,34}$

- Naglašen je značaj kvalitetnog obezbeđivanja disajnog puta, odabir odgovarajuće metode određuju karakteristike pacijenta i uvežbanost i edukovanost zdravstvenih radnika. ${ }^{35}$

- Preporuke za primenu lekova tokom kardio pulmonalne resuscitacije (KPR) nisu promenjene, ali je naglašena uloga pravilne primene celokupne palete lekova predviđenih preporukama u terapiji srčanog zastoja. ${ }^{36}$

- Rutinska primena mehaničkog KPR se ne preporučuje, ali je alternativno rešenje u situacijama kada se ne mogu postići kvalitetne kompresija grudnog koša ili kada je potrebno obezbediti sigurnost spasilaca. ${ }^{37}$

- Prehospitalna primena ultrazvuka se preporučuje za utvrđivanje reverzbilnih uzroka srčanog zastoja. ${ }^{38}$

- Primena uređaja za ekstrakorporalno ordžava-

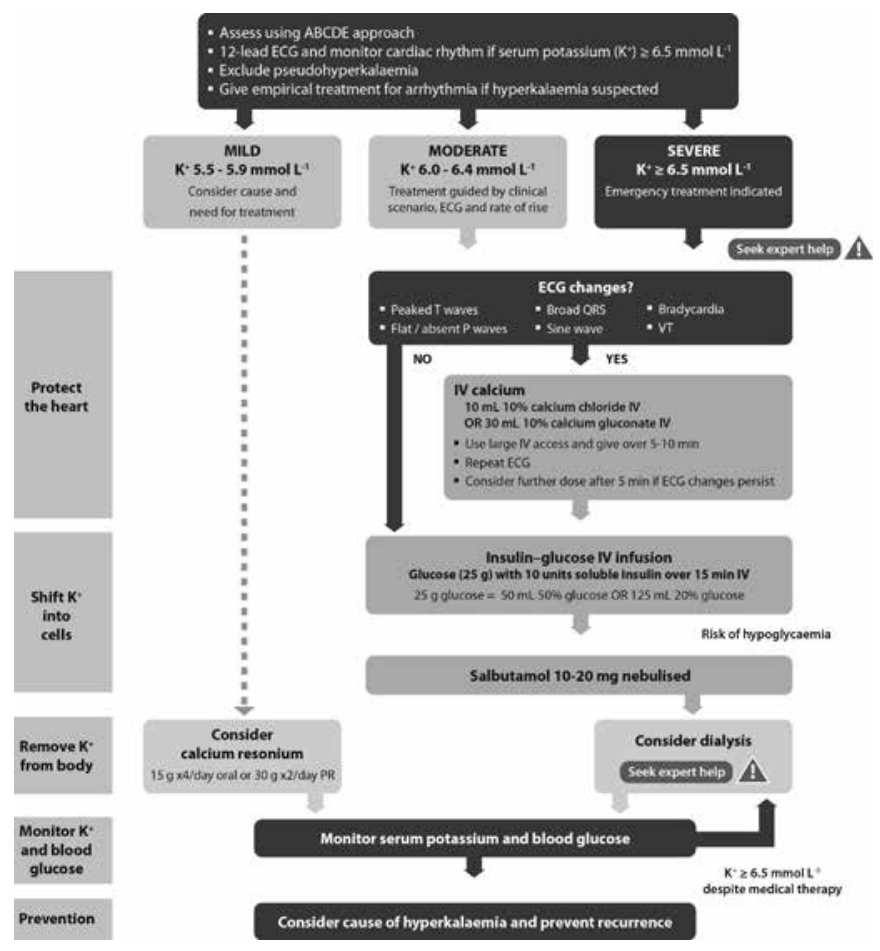

Fig.4..Algoritam lečenja hiperkalijemije

nje života - je spašavajuća mera kod pacijenata gde standardne mere ALS nisu dale rezultat. ${ }^{39}$

\section{Srčani zastoj u posebnim okolnostima}

Ovo poglavlje Preporuka 2015 sadrži prome- ne u odnosu na mere resuscitacije koje se sprovode pri zbrinjavanju srčanog zastoja u posebim okolnostima u odnosu na uzroke, uslove sredine i karakteristike samih pacijenata.

\section{Posebni uraci:}

Pod posebnim uzrocima obrađene su mere za prepoznavanje i lečenje reverzibilnih uzroka srčanog zastoja. Naglašena je potreba da se oni moraju identifikovati ili isključiti tokom zbrinjavanja srčanog zastoja. Reverzibilni uzroci su podeljeni u dve velike grupe sa po 4 uzroka u svakoj. Reverzibilne uzroke nazivamo $4 \mathrm{H}$ i 4T: hipoksija; hipo /hiperkalijemije i drugi elektrolitski poremećaji; hipo/hipertermija; hipovolemija; tenzioni pneumotoraks; tamponada (srčana); tromboza (koronarna i pulmonalna); toksini (trovanja).

- Preživljavanje asfiksijom uzrokovanog srčanog zastoja je retko a preživeli obično imaju ozbiljna neurološka oštećenja. Tokom KPR rana efektivna ventilacije pluća uz primenu kiseonika je od esencijalnog značaja. ${ }^{40}$

- Na elektrolitičke disbalanse treba stalno misliti kod pacijenata kojima preti srčani zastoj. Agresivno lečenje elektrolitskog disbalansa može prevenirati srčani zastoj. Novi algoritmi daju kliničke preporuke o urgentnom lečenju životno ugrožavajuće hiperkalijemije. $^{41}$

- Hipotermični (pothlađeni) unesrećeni bez znako-

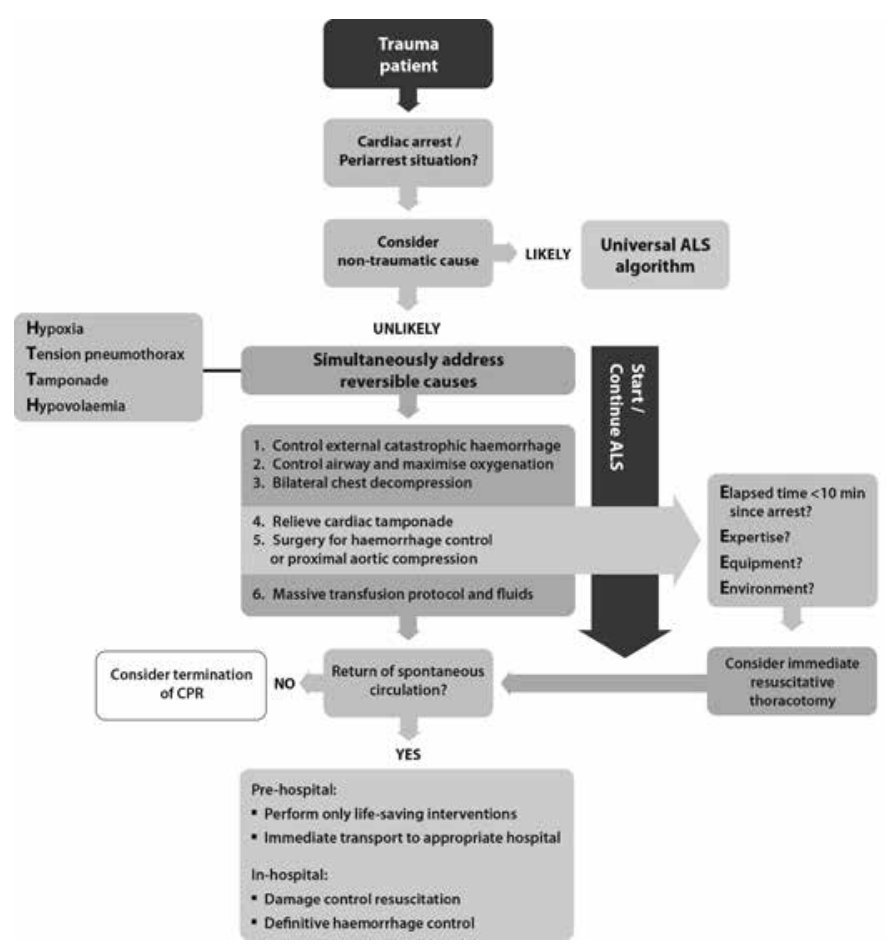

Fig.5.Algoritam lečenja traumatskog srčanog zastoja 
va srčane nestabilnosti (sistolni pritisak $>=90 \mathrm{mmHg}$, bez ventrikularnih aritmija i temperature tela $>=28^{0}$ C) mogu biti ponovo zagrejani korišćenjem neinvazinih metoda (toplim vazduhom ili toplim infuzionim rastvorima). Pothlađeni sa znacima srčane nestabilnosti trebaju biti transportovani u centre koji mogu da obezbede ekstrakorporalnu cirkulaciju (ECLS). 42

- Rano prepoznavanje i neodložno lečenje intramuskularnim adrenalinom ostaje princip urgentnog tretmana anafilaksije. ${ }^{43,44}$

- Preporukesadrže novialgoritamza tretman pacijenata sa traumatskim srčanim zastojem. Smrtnost od traumom izazvanog srčanog zastoja (TCA-traumatski srčani zastoj) je veoma visoka. Novi algoritam za TCA ukazuje na prioritete u redosledu mera pri spašavanju života. ${ }^{45,46,47,48}$

- Transport pacijenata uz kontinuiranu primenu mera kompresija grudnog koša i mehaničkom ventilacijom može biti od koristi kod pacijenata koji zahtevaju neodložnu perkutanu koronarnu intrervenciju. Ovo se odnosi na transport do specijalizovanih bolnica sa salom za kateterizaciju i kada postoje prehospitalni i intrahospitalni timovi, iskusni u mehaničkoj i hemodinamskoj podršci i perkutanoj koronarnoj intervenciji u toku KPR. 49

- Kada se kao uzrok srčanog zastoja sumnja na plućnu tromboemboliju (PTE) preporuka za primenu fibrinolitičke terapije je ne promenjena. ${ }^{50,51}$

\section{Posebni usloui sredine}

Primena mera resuscitacije u sredinama sa posebnim uslovima uključuje razmatranja tretmana srčanog zastoja koji se javlja na određenim specifičnim lokacijama. Ovo podrazumeva razmatranja za operacione sale, kardiohirurgiju, sale za $\mathrm{PCl}$, odelenja za dijalizu, stomatološke ordinacije. Razmatraju se i resuscitacione mere u komercijalnim avionima, avionskom i helikopterskom urgentnom medicinskom transportu, na sportskim objektima. Posebno se razmatraju mere resuscitacije u posebnim uslovima spoljašnjeg okruženja (npr. teško pristupačni tereni, velika nadmorska visina, lavine, udar groma i struje) ili mesta masovnih nesreća. ${ }^{52,53}$

- Nova oblast obuhvata resuscitaciju pacijenta na hiruškim odeljenjima- kod pacijenata koji su podvrgnuti hiruškim zahvatima.

Kod pacijenata koji su bili podvrgnuti kardiohiruškoj intervenciji pri primeni mera resuscitacije treba blagovremeno izvršiti urgentnu resternotomiju.

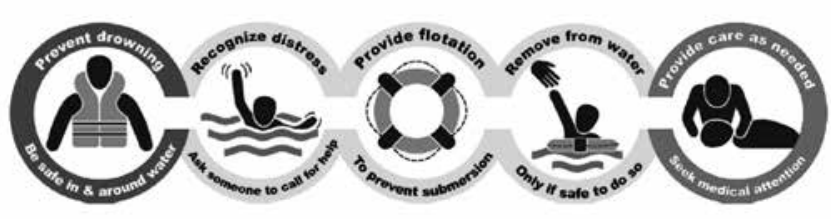

Fig. 6. Lanac za preživljavanje kod utopljenika

Posebno kada postoji sumnja na razvoj tamponade ili hemoragije a kada spoljašnje kompresije grudnog koša ne daju rezultate. ${ }^{54,55}$

- Srčani zastoj sa šokabilnim ritmom: ventrikularne fibrilacije (VF) ili ventrikularne tahikardije bez pulsa (PVT) tokom kateterizacije srca treba odmah tretirati sa tri uzastopna šoka pre početka kompresija grudnog koša. Preporučuje se upotreba aparata za mehaničku kompresiju grudnog koša tokom angiografije kako bi se osigurala kvalitetna kompresija grudnog koša i rasteretilo osoblje tokom KPR. ${ }^{56,57}$

- U stomatološkoj ordinaciji ne pomerati pacijenta iz stomatološke stolice, radi počinjanja KPR. Stomatološku stolicu treba postaviti tako da pacijent zauzima u njoj horizontalni položaj, u predelu naslona stolice postaviti podmetač da bi povećali stabilnost.

- AED uređaji i odgovarajuća oprema za primenu mera kardio pulmonalne resuscitacije mora biti obavezan deo svih komercijalnih letova aviona u Evropi uključujući regionalne i nisko budžetne avio letove. Potrebno je prilagoditi tehnike kardio pulmonalne resuscitacije ograničenom prostoru aviona. ${ }^{58,59,60,61}$

- Učestalost srčanog zastoja u helikopteru hitne medicinske pomoći (HEMS) je niska. Važnost se pridaje pripremama pre leta i upotrebi uređaja za mehaničku KPR tokom leta. ${ }^{62,63,64,65,66,67}$

- Iznenadni srčani zastoj kod sportista na terenu treba prepoznati i primeniti mere rane defibrilacije. Naglašena je potreba kvalitetnih sistematskih pregleda sportista. ${ }^{68,69}$

- Vreme od utapanja do početka resuscitacije određuje sudbinu unesrećenog. Utopljenik koji je izvađen nakon 10 minuta nema dobre izglede za preživljavanje. Očevici imaju ključnu ulogu u ranom prepoznavanju i započinjanju KPR. Strategija resuscitacije kod respiratornog srčanog zastoja daje

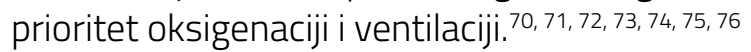

- Šanse za dobar ishod kod srčanog zastoja na teško pristupačnom terenu i planinama mogu biti smanjene zbog otežanog pristupa i dužeg transporta. Spasavanje helikopterom i korišćenje vazdušnih urgentnih ekipa može doprineti boljem preživljavanju. Upotreba AED 
uređaja u udaljenim a često posećenim mestima može doprineti boljem preživljavanju. ${ }^{77,78,79}$

- Kriterijumi za produženu KPR i ekstrakorporalno zagrevanje kod žrtava lavine koji su doživeli srčani zastoj su ograničeni. Prekid tretmana ekstrakorporalne podrške se promenio sa $>35$ min na $>60$ min trajanja zatrpavanja lavinom, sa $<32^{\circ} \mathrm{C}$ na $<30^{\circ} \mathrm{C}$, kao $\mathrm{i} \leq 12$ do $\leq 18 \mathrm{mmol} \mathrm{L^{-1 }}$ kalijuma u serumu pri prijemu $u$ bolnicu, a inače se primenjuju standardne preporuke ${ }^{80}$.

- Primeniti sigurnosne mere pri pružanju mera KPR kod žrtava elektrokucije ${ }^{81,82}$

- Tokom masovnih nesreća kada broj povređenih prevazilazi mogućnostizdravstvenih resursa neophodno je primeniti mere trijaže za sve povređene, KPR se ne primenjuje kod osoba bez znakova života.

\section{Posebna stanja}

Sekcija o posebnim stanjima daje preporuke za primenu mera KPR kod osoba sa teškim komorbiditetima (astma, srčana insuficijencija sa ventrikularnom pumpom -VADs, neurološkim bolestima, gojaznost) i sa posebnim fiziološkim stanjima (trudnice, starije osobe).

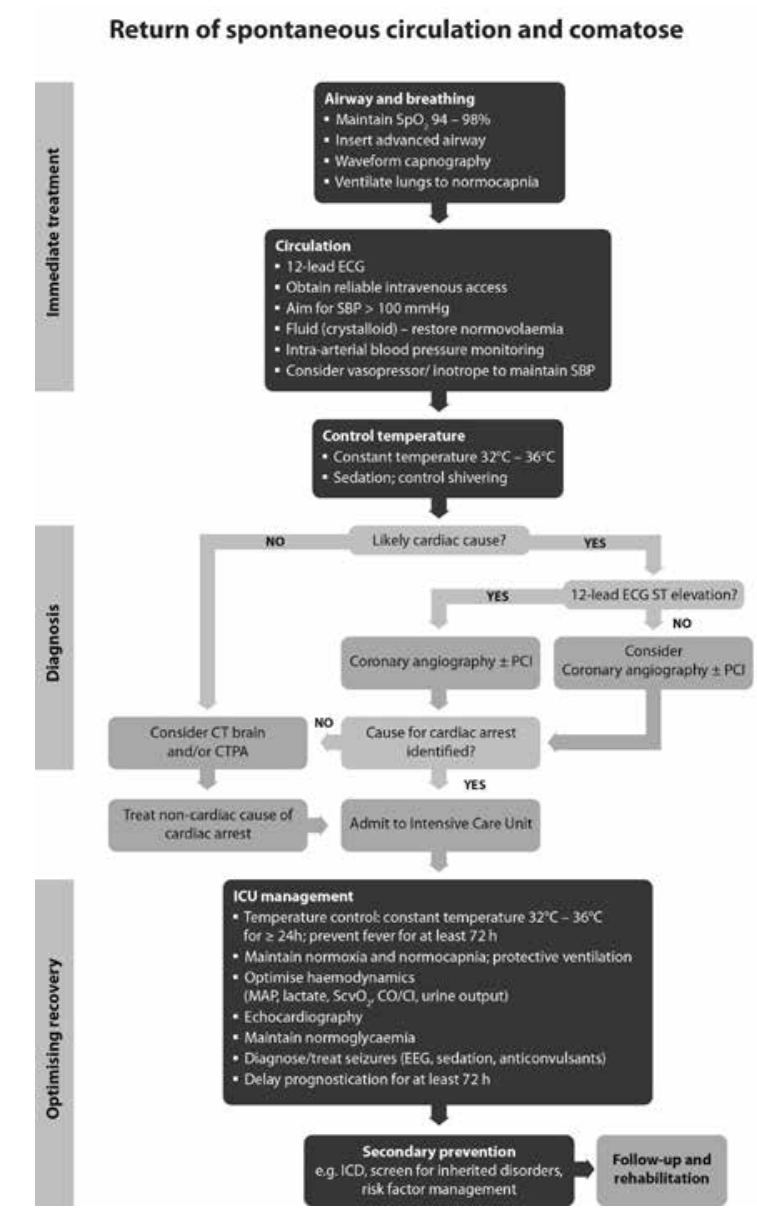

Fig. 7. Algoritam - postresuscitaciona nega
Prva linija lečenja akutnog napada astme jeste inhalacija beta-2-agonista. Intravenska primena beta-2-agonista vrši se samo kod bolesnika kojima inhalatorna terapija nije pomogla. ${ }^{83}$

Kod pacijenata sa ventrikularnom pumpom (VADs) potvrda srčanog zastoja može biti otežana. Tokom prvih 10 dana od operacije srca, ukoliko dođe do srčanog zastoja a pacijent ne reaguje na defibrilaciju, odmah obaviti resternektomiju.

Bolesnici sa subarahnoidalnim krvavljenjem mogu imati EKG promene koje ukazuju na akutni koronarni sindrom (AKS). Kod komatoznih bolesnika nakon srčanog zastoja odluka da li će se prvo vršiti kompjuterizovana tomografija (CT) pre ili posle koronarografije zavisi od kliničke odluke: subarahnoidalna hemoragija vs. akutni koronarni sindrom. ${ }^{84,85,86}$

Nema promena u preporukama za KPR gojaznih, iako KPR gojaznih može biti izazov. Razmotrite češću promenu spasilaca koji vrše kompresiju grudnog koša u odnosu na standardne dvominutne intervale. Rana endotrahealna intubacija (ETI) od strane iskusnog spasilaca se preporučuje. ${ }^{87}$

Kod trudnica koje su doživele srčani zastoj ključna intervencija jeste visoko kvalitetni KPR uz manuelno pomeranje materice, rane mere ALS kao i rano vađenje ploda ako se ne postiže rani povratak ROSC-a ostaju najvažniji postupci. $.88,89$

\section{Postresuscitaciona nega}

Ovo poglavlje je novina u preporukama; ova tema u prethodnim Preporukama bila je obuhvaćena unutar poglavlja napredne mere podrške životu(ALS). ERC je sarađivao sa predstavnicima Evropskog Udruženja Intenzivista da bi sastavio ove preporuke za postresuscitacionu negu, koje prepoznaju značaj visoko kvalitetnog postresuscitacionog tretmana kao važnu kariku lanca preživljavanja. ${ }^{90,91,92,93}$

Najznačajnije promene u postresuscitacionoj nezi u odnosu na Preporuke 2010 su sledeće:

- Veći naglasak je stavljen na potrebu za hitnom koronarnom kateterizacijom i perkutanom koronarnom intervencijom (PCI) nakon vanbolničkog srčanog zastoja verovatno kardijalnog porekla. ${ }^{94,95}$

- Kontrolisanje ciljne temperature ostaje značajno, ali sada postoji mogućnost za postizanje temperature od 36 stepeni, umesto prethodno preporučenih 32 -34 . I dalje se preporučuje prevencija groznice. ${ }^{96,97,98}$

- Prognoziranje se sada preduzima pomoću multimodalne strategije i stavljen je akcenat na dovolj- 
no vremena za neurološki oporavak i metabolisanje sedativa ${ }^{99}, 100,101$

- Novi deo je dodat koji se odnosi na rehabilitaciju posle preživljavanja srčanog zastoja. Preporuke uključuju sistemsku organizaciju praćenja i nege pacijenta koja bi trebalo da podrazumeva skrining potencijalnih kognitivnih i emocionalnih oštećenja, kao i da pruži informacije o oporavku pacijenta. ${ }^{102,103,104}$

\section{Mere žluotne podrške dece}

Preporuke 2015 sadrže deo koji se odnosi na resuscitaciju dece i novorođenčadi.

Obuhvataju sledeće celine:

1. Osnovne mere životne podrške dece

2. Postupci u zbrinjavanju teško obolelog deteta

3. Algoritam srčanog zastoja kod dece

4. Postresuscitaciona nega

Osnovne mere životne podrške dece

- Dužina insuflacije kod dece je oko 1 sekund što se podudara sa preporukama za odrasle 105, 106, 107

- Kompresije grudnog koša vrše se na donjoj polovini grudne kosti i dubina je prilagođena uzrastu deteta. Dubina kompresija grudnog koša iznosi do jedne trećine antero-posteriornog prečnika grudnog koša (do 4 $\mathrm{cm}$ za odojče i do $5 \mathrm{~cm}$ za dete). ${ }^{108,109,110}$

\section{Postupci u zbrinjauanju teško obolelog deteta}

- Ukoliko nema znakova septičnog šoka, detetu u febrilnom stanju treba kontrolisano i uz oprez nadoknađivati tečnost. Tokom nadoknade potrebno je pratiti efekte. U nekim slučajevima potrebno je individualizovati strategiju nadoknade tečnosti te se umesto slobodne nadoknade primenjuje restriktivna nadoknada tečnosti. ${ }^{111}, 112,113,114$

- Jačina energije DC šoka koja se primenjuje u kardioverziji za SVT, iznosi 1J/kg 115, 116, 117, 118.

\section{Kardiopulmonalna reanimacija}

Postupci zbrinjavanja srčanog zastoja kod dece su vrlo slični postupcima kod odraslih dok je doza leka prilagođena telesnoj masi deteta.

\section{Zbrinjauanje srčanog zastoja kod dece}

Mnogi postupci u zbrinjavanju srčanog zastoja kod dece su isti onima kod odraslih.

\section{Postresuscitaciona nega kod dece}

- Potrebno je sprečiti nastanak groznice kod dece sa ROSC u vanbolničkim uslovima. ${ }^{119}$

- Ciljna temperatura kod dece sa uspostavljenim ROSC-om bi trebalo da podrazumeva normotermiju ili blagu hipotermiju 120, 121

- Preporukama nije jasno određeno kada prekinuti resuscitaciju kod deteta.

\section{Mere žluotne podrške i resuscitacija novorodenčadí}

$\mathrm{U}$ ovom dokumentu navedene su glavne izmene u preporuka 2015 koje se odnose na resuscitaciju novorodenčadi.

- Prilikom vođenja porođaja potrebno je prepoznavati specifične situacije u kojima je novorođenčetu potrebno pružiti napredne mere podrške životu

Mere resuscitacije tokom porođaja: Potrebno je prepoznati jedinstvene situacije tokom porođaja koje ukazuju da će plod zahtevati medicinsku pomoć neposredno posle porođaja. Termin podrška tokom porođaja uvodi se radi boljeg naglašavanja intervencija koje su neophodne za uspostavljanje funkcije vitalnih organa (resuscitacije, podrške tokom rođenja)

- Preporuke 2015 preporučuju odlaganje u podvezivanju pupčane vrpce: od najmanje 1 minute od momenta potpunog rođenja ploda, za ročnu i prevremeno rođenu decu. Ovo se odnosi na decu čije vitalne funkcije nisu ugrožene. Još uvek nema jasnih podataka koji preporučuju adekvatno vreme podvezivanja pupčanika kod ploda koji zahteva resuscitaciju. ${ }^{122}$

- Preporučuje se da se telesna temperatura novorođenčadi koja nisu imala asfiksiju održava u okvirima od 36.5 do 37.5 neposredno posle rođenja. Temperatura na rođenju treba da se beleži i značajan je indikator kvaliteta zdravstvenog sistema. ${ }^{123,124 .}$

- Održavanje telesne temperatureod 36,5 do 37,5 dece rođene pre 32 nedelje može biti zahtevno. Ovo se postiže primenom zagrejanog, vlažnog vazduha postavljanjem deteta u zagrejanu prostoriju uz uvijanje tela i glave deteta u toplotni omotač načinjen od plastike, odnosno primenom termalnog dušeka.

- Mere optimalizovanja srčane frekvence: Kod novorođenčadi koja zahtevaju resuscitaciju, preporučuje su snimanje EKG kako bi se obezbedila brza i precizna procena srčane frekvence ${ }^{125,126,127}$

- Endotrahealna intubacija (ETI) novorođenčeta nije rutinska metoda obezbeđivanja disajnog puta u prisu- 


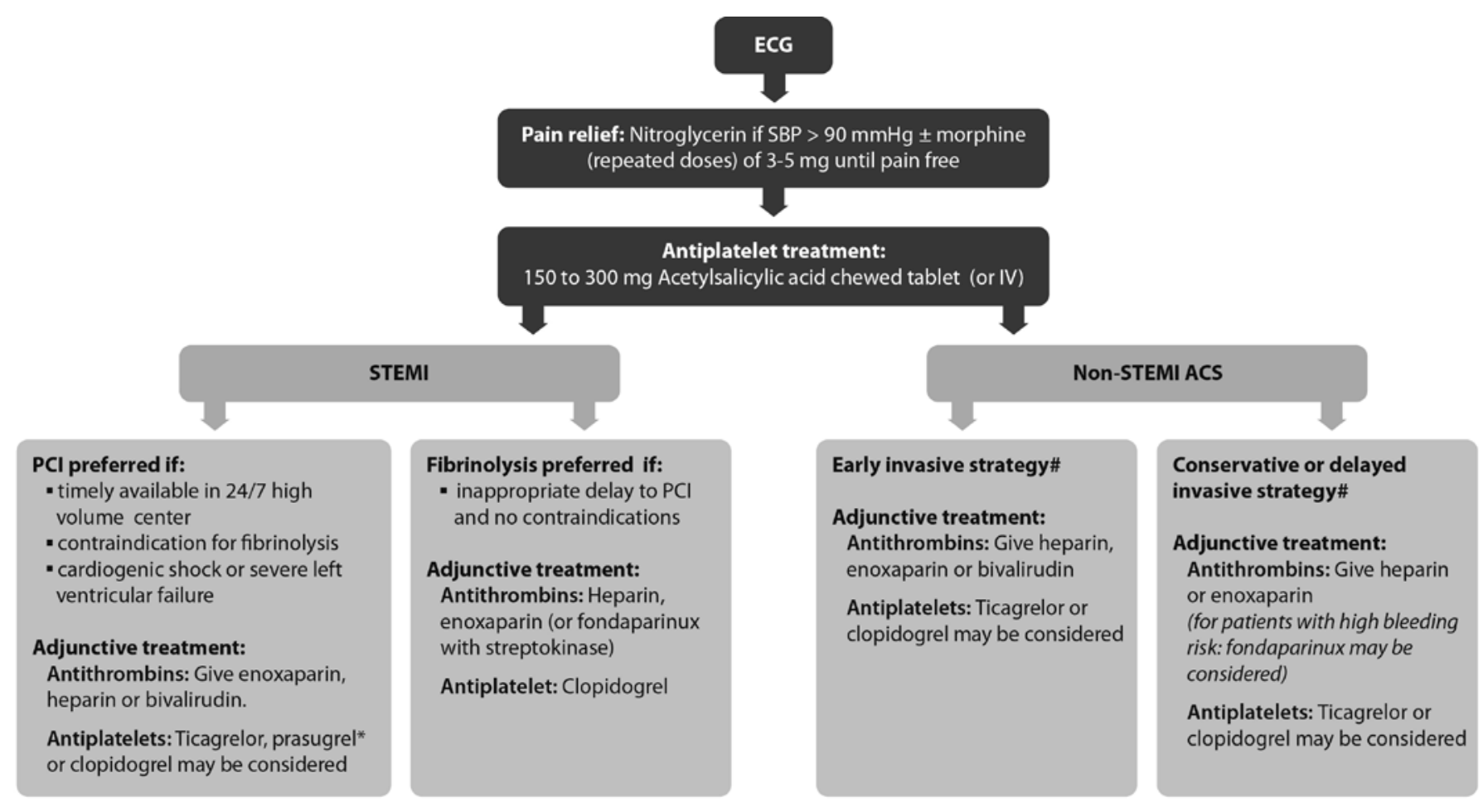

(*Increased intranial bleeding rates with prasugrel in pts. with a history of stroke or TIA, in pts $>75$ years of age and $<60 \mathrm{~kg}$ body weight) \#According to stratification

Fig.8.Tretman ACS

stvu mekonijuma u disajnom putu, već je treba primeniti samo u slučaju sumnje na trahealnu opstrukciju. $U$ Preporukama 2015 naglasak je na započinjanju ventilacije novorođenčadi u toku prvog minuta života ako ono ne diše ili ne diše efikasno i to se ne sme odlagati 128, 129, 130.

- Mere podrške disanja kod ročnog novorođenčeta bi trebalo otpočeti primenom vazduha. Kod prevremeno rođene dece preporučuje se upotreba inicijalno samo vazduhaili niske koncentracije kiseonika, do 30\% .Kada uprkos efektivnoj ventilaciji oksigenacija (idealno praćena pulsnom oksimetrijom) ostaje ne prihvatljivo niska treba razmotriti primenu viših koncentracija kiseonika. ${ }^{131}, 132,133$.

- Kod prevremeno rođenog deteta sa respiratornim distres sindromom, inicijalnu respiratornu potporu spontanom disanju obezbediti upotrebom CPAP metode ventilacije pre nego endotrahealnom intubacijom $134,135,136$.

\section{Akutni koronarni sindromi}

Preporuke koje se odnose na akutne koronarne sindrome obuhvataju:

1. Dijagnostičke procedure kod AKS
2. Terapijske procedure AKS

3. Strategija reperfuzije kod STEMI

4. Reperfuziona strategija u bolničkim uslovima

Sledeća celina je rezime najvažnijih promena u Preporukama 2015 za dijagnozu i tretman akutnih koronarnih sindroma u Preporuke 2010.

\section{Dijagnostičke procedure kod AKS}

- Kod svakog pacijenta sa sumnom na akutni infarkt miokarda sa ST elevacijom preporučuje se prehospitalno snimanje 12-kanalnog EKG. Ova dijagnostička metoda smanjuje kako prehospitalni tako i intrahospitalni mortalitet.

Kompjuterska analiza EKG zapisa preporučuje se kada lekar nije prisutan na terenu ako je kvalitet ove metode obezbeđen odgovarajućim programom. ${ }^{137,138}$

- Preporučuje se aktivacija kateterizacione laboratorije sa terena u slučaju STEMI jer to može ne samo da skrati vreme do PCl pacijenta već i da smanji mortalitet. ${ }^{139,140,141,142}$

- Preporuke 2015 ukazuju da se negativni rezultati visoko senzitivnih troponina (HS-CTN) ne mogu koristiti kao jedini marker za isključivanje postojanjaAKS,ali kod 
pacijenata sa niskim skor rizikom mogu opravdati raniji otpust. $^{143}$

\section{Terapijske procedure u AKS}

- Kod pacijenata sa STEMI koji su planirani za primarni $\mathrm{PCl}$ mogu se dati antagonisti receptora adenozin difosfata (klopidogrel, tikagrelol, prasugrel) prehospitalno ili na urgentnim odeljenjima.

- Pored ovoga, pacijentima sa STEMI koji su planirani za $\mathrm{PCl}$ može se dati nefrakcionisani heparin (UFH) prehospitalno ili na urgentnim odeljenjima. ${ }^{144,145}$

- U prehospitalnim uslovima enoksaparin se može koristiti kao alternativa nefrakcionisanom heparinu (UFH) kod pacijenata sa STEMI.

- Preporuke 2015 ističu da se kod pacijenata sa akutnim bolom u grudima i sumnjom na AKS ne primenjuje rutinski kiseonik ukoliko pacijent nema znake hipoksije, dispneje ili popuštanja srca. ${ }^{146,147,148}$

\section{Strategija reperfuzione terapije kod STEMI}

Odluke o primeni reperfuzione terapije su prilagođene lokalnim uslovima:

- U slučaju kada je vreme transporta pacijenta duže od 30 minuta, a prehospitalno osoblje dobro edukovano, preporučena je prehospitalno reperfuziona terapija primenom fibrinolize. ${ }^{149,150}$

- U onim regijama gde postoje $\mathrm{PCl}$ dostupni centri ova intervencija ima prednost u odnosu na prehospitalnu fibrinolizu.

- Pacijente sa STEMI na urgetnom odeljenju bolnice koja ne poseduje $\mathrm{PCl}$ jedinice, treba transportovati neodložno u najbliži $\mathrm{PCl}$ centar uz uslov da se $\mathrm{PCl}$ može uraditi za manje od 120 minuta (odnosno unutar 60-90 minutaod početka simptoma, kod pacijenata sa proširenim IM). ${ }^{151,152}$

- Kod pacijenata koji su primili fibrinolitičku terapiju u bolnicama bez $\mathrm{PCl}$ centra preporučuje se rana rutinska angiografija (od 3do 24 sata od primene fibrinolitičke terapije) i ranije u slučaju kada ishemija perzistira. ${ }^{153}$

- PCI nakon primene fibrinolitičke terapije vrši se najranije tri sata po primeni fibrinolize, a ranije samo u slučaju neuspele fibrinolitičke tarapije. ${ }^{154}$

\section{Strategija reperfuzione terapije u bolničkim uslouima, nakon resuscitacije posle pouratka spontane cirkulacije}

- Kod pacijenata sa ROSC koji su doživeli vanbolnički srčani zastoj - srčanog porekla i sa prisutvom ST elevacije na EKG-u, preporučuje se hitna evaluacija stanja u kateterizacionoj laboratoriji uz primenu $\mathrm{PCI}$. Ova strategija identična je i za pacijenata sa STEMI bez srčanog zastoja. ${ }^{155,156,157}$

- Kod komatoznih pacijenata sa ROSC koji su doživeli vanbolnički srčani zastoj kada postoji sumnja na srčano poreklo zastoja bez ST-elevacije na EKG-u, potrebno je razmotriti hitnu kateterizaciju. ${ }^{158}$

\section{Prua pomoć}

Poglavlje Prva pomoć je novost u Preporukama. Prva pomó́ se definiše kao skup mera i postupaka u inicijalnom tretmanu akutno obolele ili povređene osobe.

Prvu pomoć može da pruža bilo ko, u bilo kojoj situaciji.

Osoba koja pruža prvu pomoć definiše se kao osoba koja je obučena da:

- prepozna, proceni i utvrdi da postoji potreba za pružanjem prve pomoći

- pruži adekvatnu prvu pomoć

- prepoznaje ograničenja u ljudstvu i opremi i prepozna kada treba tražiti stručnu pomoć

Cilj mera prve pomoći jeste da se pacijent održi u životu,da mu se ublaži patnja te spreči pogoršanje bolesti i obezbedi oporavak.

Definicija prve pomoći, utvrđena je 2015. godine od strane Radne grupe za prvu pomoć ILCOR komiteta.

\section{Načela edukacije u resuscitaciji}

U oblasti edukacije u resuscitaciji posebno je naglašena važnost treninga i implementacija znanja i veština.

\section{Trening}

- Preporučuje se upotreba i nabavka visoko kvalitetnih, tehnološko razvijenih manekena. Upotreba manje tehnološko razvijenih manekena je takođe prikladna za sve nivoe treninga ERC kurseva. ${ }^{159}$

- Povratne informacije (KPR feedback) su korisne za brže usvajanje tehnike kvalitetnih kompresija grudnog koša (brzina,dubina, relaksacija grudnog koša i položaj ruku). Korišćenje samo tonskog uređaja za praćenje 
učestalosti kompresija grudnog koša može negativno uticati na kvalitet kompresija po dubini. ${ }^{160,} 161$

- Učestalost retreninga se razlikuje u zavisnosti od kandidata (spasilaci ili zdravstveni profesionalci). Dokazano je da se veštine KPR gube već nakon mesec dana od treninga. Retreninzi predviđeni kao jednogodišnji nisu dovoljni. Optimalni interval za retrening nije utvrđen, no postoje dokazi da česti "nisko-dozni" treninzi mogu biti od koristi. ${ }^{162,163}$

- Treninzi netehničkih veština (komunikacione veštine, veština vođenja tima i uloga pojedinih članova tima) je suštinski dodatak u učenju veština resuscitacije. Ova vrsta obuke treba da se uvrsti u redovne kurseve. ${ }^{164,}$ 165

- Dispečer hitne medicinske pomoći dobija sve veću ulogu u prepoznavanju i vođenju laika za započinjanje KPR. Ova nova uloga zahteva poseban trening radi pružanja jasnih i korisnih instrukcija u stresnim situacijama. ${ }^{166}$

\section{Implementacija}

- Povratne informacije imaju za cilj unapređenje rada KPR timova. Posebno se preporučuje njihova primena za timove koji zbrinjavaju srčani zastoj. ${ }^{167}$

- Regionalni sistemi uključuju Centre za srčani zastoj sa ciljem poboljšanja ishoda i smanjenja neurološkog deficita kod vanbolničkih srčanih zastoja. ${ }^{168,169}$

- Upotreba novih tehnologija i veća društvena svest može da utiče na poboljšanje brzog reagovanja kod vanbolničkog srčanog zastoja. Novi sistemi se preporučuju za informisanje očevidaca o lokaciji najbližeg AED uređaja. Svaka tehnologija koja unapređuje brže reagovanje očevidaca i brži pristup najbližem AED uređaju biće prihvaćena. ${ }^{170,171}$

- "Potrebno je sistemom spašavati život"-http:// www.resuscitationacademy.com/Zdravstveni sistem treba da ima veću odgovornost za zbrinjavanje bolesnika sa srčanim zastojem (npr.Službe hitne medicinske pomoći, Centri za srčani zastoj), proceniti njihov rad i obezbediti bolje uslove za rad radi postizanja veće stope preživljavanja.

\section{Resuscitaciona etika i odluke u resuscitaciji}

Odluke o resuscitaciji u ERC Preporukama 2015 obuhvataju detaljnu raspravu o etičkim principima koji podržavaju kardio pulmonalnu reanimaciju.

Postoji napredak u odnosu na tradicionalni pristup sa medicinskog stanovišta koje naglašava dobrobit pacijenta i u većoj meri uvažava njegovu autonomiju .

Ovakav napredak je rezultirao spremnošću da se postigne razumevanje i interakcija između pacijenata i zdravstvenih radnika.

Dok je realnost takva da većina osoba koje su doživele srčani zastoj ne preživi, nedavne studije dale su dokaze o postojanom poboljšanju rezultata primene mera KPR, naročito tamo gde je pravilno primenjena formula preživljavanja. Posebni slučajevi refrakternih srčanih zastoja koji bi u prošlosti bili fatalni, mogu imati koristi od dodatnog interventnog pristupa. Dalji napredak u preživljavanju može se očekivati uz primenu jasnih vodiča za započinjanje, nezapočinjanje, prekidanje i odustajanje od pokušaja resuscitacije i uz prepoznavanje refraktarnih slučajeva koji mogu odgovoriti na primenu naprednih intervencija.

Tradicionalni etički principi su opisani u kontekstu pristupa ka reanimaciji sa stanovišta pacijenta.

Samostalnost, podrazumeva poštovanje ličnih prioriteta što je izraženo u Preporukama 2015, što nagoveštava precizne informacije i komunikaciju. ${ }^{172,173,}$ 174,175

Dobrobit, podrazumeva razmatranje započinjanja, nezapočinjanja, KPR tokom transporta, specijalna stanja, sa jasnom razlikom između iznenadnog srčanog zastoja i očekivanog prestanka rada srca i disanja u terminalnim stanjima ${ }^{176,177}$

Neškodljivost, uključujući "DNAR/DNACPR" (ne pokušavajte reanimaciju/ne pokušavajte $K P R$ ), kada prestati/odustati i učešće pacijenta ili zastupnika. ${ }^{178,179}$

Pravednost i jednaka pristupačnost, uključujući izbegavanje nejednakosti

Evropa je mozaik od 47 zemalja sa razlikama u zakonodavstvu, sudstvu, kulturi, religiji i ekonomskoj moći. Evropske zemlje tumače etičke preporuke o resuscitaciji u kontekstu ovih faktora. Pregled sadašnje prakse širom Evrope predstavljen u ovim smernicama prepoznaje značajnu varijabilnost u pristupu KPR-u i dokumentaciji smrtnog ishoda. Potreba za usklađivanjem u zakonodavstvu, sudstvu, terminologiji i praksi je i dalje prisutna.

Resuscitaciona infrastruktura zasnovana na timovima, precizno i uniformno izveštavanje o pokušajima resuscitacije i objavljivanje resuscitacionih intervencija u nacionalnim/ multinacionalnim registrima, kao i multicentrične kliničke studije mogu doprineti poboljšanju kvaliteta KPR i ishoda srčanog zastoja.

Za razvoj budućih Preporuka, poželjno je dalje 
aktivno uključivanje svih zainteresovanih strana, javnosti, pacijenata, preživelih, društva i stručnih udruženja kao aktivnih partnera u ovom procesu.

\section{Reference}

1. Perkins GD, Handley AJ, Koster KW, et al. European Resuscitation Council Guidelines for Resuscitation 2015 Section 2. Adult basic life support and automated external defibriIlation.Resuscitation 2015, http://dx.doi.org/10.1016/j. resuscitation.2015.07.015.

2. Soar J, Nolan JP, Bottiger BW, et al. European Resuscitation Council Guidelines for Resuscitation 2015 Section 3. Adult advanced life support. Resuscitation 2015, http://dx.doi.org/10.1016/j.resuscitation.2015.07.016.

3. Truhlar A, Deakin CD, Soar J, et al. European Resuscitation Council Guidelines for Resuscitation 2015 Section 4. Cardiac arrestin special circumstances.Resuscitation 2015, http://dx.doi.org/10.1016/j.resuscitation.2015.07.017.

4. Nolan JP, Soar J, Cariou A, et al. European Resuscitation Council Guidelines for Resuscitation 2015 Section 5. Post resuscitation care. Resuscitation 2015, http://dx.doi.org/10.1016/j.resuscitation.2015.07.018.

5. Maconochie I, Bingham R, Eich C, et al. European Resuscitation Council Guidelines for Resuscitation 2015 Section 6. Paediatric life support.Resuscitation 2015, http://dx.doi.org/10.1016/j.resuscitation.2015.07.028.

6. Wyllie J, Jos Bruinenberg J, Roehr CC, Rüdiger M, Trevisanuto D. B.U. European Resuscitation Council Guidelines for Resuscitation 2015 Section 7. Resuscitation and support of transition of babies at birth.Resuscitation 2015, http:// dx.doi.org/10.1016/j.resuscitation.2015.07.029.

7. Nikolaou NI, Arntz HR, Bellou A, Beygui F, Bossaert LL, Cariou A. European Resuscitation Council Guidelines for Resuscitation 2015 Section 8. Initial management of acute coronary syndromes. Resuscitation 2015, http://dx.doi.org/10.1016/j.resuscitation.2015.07.03

8. Zideman DA, De Buck EDJ, Singletary EM, et al. European Resuscitation Council Guidelines for Resuscitation 2015 Section 9. First aid. Resuscitation 2015, http://dx.doi.org/10.1016/j.resuscitation.2015.07.031.

9. Greif R, Lockey AS, Conaghan P, Lippert A, De Vries W, Monsieurs KG. European Resuscitation Council Guidelines for Resuscitation 2015 Section 10.Principles of education in resuscitation.Resuscitation 2015, http://dx.doi.org/10.1016/j.resuscitation.2015.07.032.

10. Bossaert L, Perkins GD, Askitopoulou H, et al. European Resuscitation Council Guidelines for Resuscitation 2015 Section 11. The ethics of resuscitation and end-of-life decisions.Resuscitation 2015, http://dx.doi.org/10.1016/j. resuscitation.2015.07.033.

11. Bohm K, Rosenqvist $M$, Hollenberg J, Biber B, Engerstrom L, Svensson L. Dispatcher-assisted telephone-guided cardiopulmonary resuscitation: an underused lifesaving system. Eur J Emerg Med: Off J Eur Soc Emerg Med 2007;14:256-9.

12. Vaillancourt C, Verma A, Trickett J, et al. Evaluating the effectiveness of dispatch-assisted cardiopulmonary resuscitation instructions. Acad Emerg Med: Off J Soc Acad Emerg Med 2007;14:877-83.

13. Tanaka $Y$, Taniguchi J, Wato $Y$, Yoshida $Y$, Inaba $H$. The continuous quality improvement project for telep- hone-assisted instruction of cardiopulmonary resuscitation increased the incidence of bystander CPR and improved the outcomes of out-of-hospital cardiac arrests. Resuscitation 2012;83:1235-41.

14. Stipulante $S$, Tubes $R$, El Fassi $M$, et al. Implementation oftheALERT algorithm, a new dispatcher-assisted telephone cardiopulmonary resuscitation protocol, in non-Advanced Medical Priority Dispatch System (AMPDS) Emergency Medical Services centres. Resuscitation 2014;85:177-81.

15. Ringh $M$, Rosenqvist $M$, Hollenberg J, et al. Mobile-phone dispatch of laypersons for CPR in out-of-hospital cardiac arrest. N Engl J Med 2015;372:2316-25.

16. van Alem AP, Vrenken RH, de Vos R, Tijssen JG, Koster RW. Use of automated external defibrillator by first responders in out of hospital cardiac arrest: prospective controlled trial. BMJ 2003;327:1312

17. Clawson J, Olola C, Heward A, Patterson B. Cardiac arrest predictability in seizure patients based on emergency medical dispatcher identification of previous seizure or epilepsy history. Resuscitation 2007;75:298-304.

18. Rea TD, Fahrenbruch C, Culley L, et al. CPR with chest compresssions alone or with rescue breathing. N Engl J Med 2010;363:423-33.

19. Svensson L, Bohm K, Castren M, et al. Compression-only CPR or standard CPR in out-of-hospital cardiac arrest. N Engl J Med 2010;363:434-42.

20. IdrisAH, Guffey D,Aufderheide TP, et al.Relationshipbetweenchest compression rates and outcomes from cardiac arrest. Circulation 2012;125:3004-12.

21. 5. Nichol G, Valenzuela T, Roe D, Clark L, Huszti E, Wells GA. Cost effectiveness of defibrillation by targeted responders in public settings. Circulation 2003;108:697-703

22. Folke F, Lippert FK, Nielsen SL, et al. Location of cardiac arrest in a city center: strategic placement of automated external defibrillators in public locations. Circulation 2009;120:510-7

23. Kitamura T, Iwami T, Kawamura $T$, et al. Conventional and chestcompression-only cardiopulmonary resuscitation by bystanders for children who have out-of-hospital cardiac arrests: a prospective, nationwide, population-based cohort study. Lancet 2010;375:1347-54

24. Ruben $\mathrm{H}$, Macnaughton Fl. The treatment of food-choking. Practitioner 1978;221:725-9

25. Guildner CW, Williams D, Subitch T. Airway obstructed by foreign material: the Heimlich maneuver. JACEP 1976;5:675-7.

26. Langhelle A, Sunde K, Wik L, Steen PA. Airway pressure with chest compressions versus Heimlich manoeuvre in recently dead adults with complete airway obstruction. Resuscitation 2000;44:105-8.

27. Soreide $E$, Morrison $L$, Hillman $K$, et al. The formula for survival in resuscitation. Resuscitation 2013;84:1487-93.

28. Soreide $E$, Morrison L, Hillman $K$, et al. The formula for survival in resuscitation. Resuscitation 2013;84:1487-93.

29. Deakin CD, Nolan JP, Soar J, et al. European Resuscitation Council Guidelines for Resuscitation 2010 Section 4. Adult advanced life support. Resuscitation 2010;81:1305-52.

30. Nolan J, Soar J, Eikeland H. The chain of survival. Resuscitation 2006;71: 270-1.

31. Smith GB. In-hospital cardiac arrest: is it time for an in-hospital 'chain of prevention'? Resuscitation 2010. 
32. Giberson B, Uber A, Gaieski DF, et al. When to stop CPR and when to perform rhythm analysis: potential confusion among ACLS providers. J Intensive Care Med 2014

33. Sheak KR, Wiebe DJ, Leary $M$, et al. Quantitative relationship between end-tidal carbon dioxide and CPR quality during both in-hospital and outof-hospital cardiac arrest. Resuscitation 2015;89:149-54

34. Pokorna M, Necas E, Kratochvil J, Skripsky R, Andrlik M, Franek 0 . A sudden increase in partial pressure end-tidal carbon dioxide (P(ET)CO(2)) at the moment of return of spontaneous circulation. J Emerg Med 2010;38:614-21.

35. Fouche PF, Simpson PM, Bendall J, Thomas RE, Cone DC, Doi SA. Airways in out-of-hospital cardiac arrest: systematic review and meta-analysis. Prehosp Emerg Care: Off J Natl Assoc EMS Phys Natl Assoc State EMS Dir 2014;18:244-56

36. Olasveengen TM, Sunde $K$, Brunborg C, Thowsen J, Steen PA, Wik L. Intravenous drug administration during out-of-hospital cardiac arrest: a randomized trial. JAMA 2009;302:2222-9.

37. Couper K, Smyth M, Perkins GD. Mechanical devices for chest compression: to use or not to use? Curr Opin Crit Care 2015;21:188-94

38. Narasimhan M, Koenig SJ, Mayo PH. Advanced echocardiography for the critical care physician: Part 1. Chest 2014;145:129-34

39. Riggs KR, Becker LB, Sugarman J. Ethics in the use of extracorporeal cardiopulmonary resuscitation in adults. Resuscitation 2015;91:73-5

40. Soar J, Callaway CW, Aibiki M, et al. Part 4: Advanced life support: 2015 International Consensus on Cardiopulmonary Resuscitation and Emergency Cardiovascular Care Science With Treatment Recommendations. Resuscitation 2015. $X X: X X$

41. Soar J, Perkins GD, Abbas G, et al. European Resuscitation Council Guidelines for Resuscitation 2010 Section 8. Cardiac arrest in special circumstances: electrolyte abnormalities, poisoning, drowning, accidental hypothermia, hyperthermia, asthma, anaphylaxis, cardiac surgery, trauma, pregnancy, electrocution. Resuscitation 2010;81:1400-33.

42. Gruber E, Beikircher W, Pizzinini R, et al. Non-extracorporeal rewarming at a rate of 6.8 degrees $C$ per hour in a deeply hypothermic arrested patient. Resuscitation 2014;85:e119-20.

43. Simpson CR, Sheikh A. Adrenaline is first line treatment for the emergency treatment of anaphylaxis. Resuscitation 2010;81:641-2.

44. Kemp SF, Lockey RF, Simons FE. Epinephrine: the drug of choice for anaphylaxis. A statement of the World Allergy Organization. Allergy 2008;63:1061-70.

45. Zwingmann J, Mehlhorn AT, Hammer T, Bayer J, Sudkamp NP, Strohm PC. Survival and neurologic outcome after traumatic out-of-hospital cardiopulmonary arrest in a pediatric and adult population: a systematic review. Crit Care 2012;16:R117

46. Leis CC, Hernandez CC, Blanco MJ, Paterna PC, Hernandez Rde E, Torres EC. Traumatic cardiac arrest: should advanced life support be initiated? J Trauma Acute Care Surg 2013;74:634-8

47. Lockey D, Crewdson K, Davies G. Traumatic cardiac arrest: who are the survivors? Ann Emerg Med 2006;48:240-4

48. Crewdson K, Lockey D, Davies G. Outcome from paedia- tric cardiac arrest associated with trauma. Resuscitation 2007;75:29-34.

49. 6. Stub D, Nehme Z, Bernard S, Lijovic M, Kaye DM, Smith $K$. Exploring which patients without return of spontaneous circulation following ventricular fibrillation out-of-hospital cardiac arrest should be transported to hospital? Resuscitation 2014;85:326-31.

50. Böttiger BW, Martin E. Thrombolytic therapy during cardiopulmonary resuscitation and the role of coagulation activation after cardiac arrest. Curr Opin Crit Care 2001;7:176-83

51. Kurkciyan I, Meron G, Sterz F, et al. Pulmonary embolism as a cause of cardiac arrest: presentation and outcome. Arch Intern Med 2000; 160:1529-35.

52. Ellis SJ, Newland MC, Simonson JA, et al. Anesthesia-related cardiac arrest. Anesthesiology 2014;120:829-38.

53. Gonzalez LP, Braz JR, Modolo MP, de Carvalho LR, Modolo NS, Braz LG. Pediatric perioperative cardiac arrest and mortality: a study from a tertiary teaching hospital. Pediatr Crit Care Med: J Soc Crit Care Med World Feder Pediatr Intensive Crit Care Soc 2014;15:878-84.

54. Charalambous CP, Zipitis CS, Keenan DJ. Chest reexploration in the intensive care unit after cardiac surgery: a safe alternative to returning to the operating theater. Ann Thorac Surg 2006;81:191-4.

55. LaPar DJ, Ghanta RK, Kern JA, et al. Hospital variation in mortality from cardiac arrest after cardiac surgery: an opportunity for improvement? Ann Thorac Surg 2014;98:534-9 [discussion 9-40].

56. Wagner $H$, Terkelsen CJ, Friberg $H$, et al. Cardiac arrest in the catheterisation laboratory: a 5-year experience of using mechanical chest compressions to facilitate $\mathrm{PCl}$ during prolonged resuscitation efforts. Resuscitation 2010;81:383-7.

57. Larsen Al, Hjornevik AS, Ellingsen CL, Nilsen DW. Cardiac arrest with continuous mechanical chest compression during percutaneous coronary intervention. $A$ report on the use of the LUCAS device. Resuscitation 2007;75:454-9

58. O'Rourke MF, Donaldson E, Geddes JS. An airline cardiac arrest program. Circulation 1997;96:2849-53.

59. Page $R L$, Joglar JA, Kowal $R C$, et al. Use of automated external defibrillators by a U.S. airline. N Engl J Med 2000;343:1210-6.

60. Graf J, Stuben U, Pump S. In-flight medical emergencies. Dtsch Arztebl Int 2012;109:591-601 [quiz 2].

61. 8. Brown AM, Rittenberger JC, Ammon CM, Harrington $S$, Guyette FX. In- flight automated external defibrillator use and consultation patterns. Prehosp Emerg Care: Off J Natl Assoc EMS Phys Natl Assoc State EMS Dir 2010;14:235-9

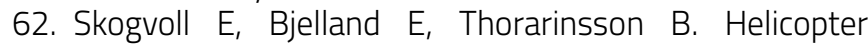
emergency medical service in out-of-hospital cardiac arrest - a 10-year population-based study. Acta Anaesthesiol Scand 2000;44:972-9.

63. Lyon RM, Nelson MJ.Helicopter emergency medical services (HEMS) response to out-of-hospital cardiac arrest. Scand J Trauma Resusc Emerg Med 2013;21:1.

64. Forti A, Zilio G, Zanatta $P$, et al. Full recovery after prolonged cardiac arrest and resuscitation with mechanical chest compression device during helicopter transportation and percutaneous coronary intervention. J Emerg Med 2014;47:632-4.

65. Pietsch U, Lischke $V$, Pietsch C. Benefit of mechanical 
chest compression devices in mountain HEMS: lessons learned from 1 year of experience and evaluation. Air Med J 2014;33:299-301

66. Omori $K$, Sato $S$, Sumi $Y$, et al. The analysis of efficacy for AutoPulse system in flying helicopter. Resuscitation 2013;84:1045-50.

67. Putzer G, Braun P, Zimmermann A, et al. LUCAS compared to manual cardiopulmonary resuscitation is more effective during helicopter rescuea prospective, randomized, crossover manikin study. Am J Emerg Med 2013;31:384-9.

68. Harmon KG, Drezner JA, Wilson MG, Sharma S. Incidence of sudden cardiac death in athletes: a state-of-the-art review. Heart 2014;100:1227-34.

69. Corrado D, Drezner J, Basso C, Pelliccia A, Thiene G. Strategies for the prevention of sudden cardiac death during sports. Eur J Cardiovasc Prev Rehabil: Off J Eur Soc Cardiol Work Groups Epidemiol Prev Cardiac Rehabil Exerc Physiol 2011;18:197-208

70. Lin CY, Wang YF, Lu TH, Kawach I. Unintentional drowning mortality, by age and body of water: an analysis of 60 countries. Inj Prev 2015;21:e43-50

71. Szpilman D, Webber J, Quan L, et al. Creating a drowning chain of survival. Resuscitation 2014;85:1149-52.

72. Vahatalo R, Lunetta P, Olkkola KT, Suominen PK. Drowning in children: Utstein style reporting and outcome. Acta Anaesthesiol Scand 2014;58:604-10.

73. Claesson A, Lindqvist J, Herlitz J. Cardiac arrest due to drowning - changes over time and factors of importance for survival. Resuscitation 2014;85:644-8

74. Claesson A, Lindqvist J, Herlitz J. Cardiac arrest due to drowning - changes over time and factors of importance for survival. Resuscitation 2014;85:644-8

75. Dyson K, Morgans A, Bray J, Matthews B, Smith K. Drowning related out-of-hospital cardiac arrests: characteristics and outcomes. Resuscitation 2013;84:1114-8.

76. Tipton MJ, Golden FS. A proposed decision-making guide for the search, rescue and resuscitation of submersion (head under) victims based on expert opinion. Resuscitation 2011;82:819-24.

77. Tomazin I, Ellerton J, Reisten O, Soteras I, Avbelj M. International Commission for Mountain Emergency M. Medical standards for mountain rescue operations using helicopters: official consensus recommendations of the International Commission for Mountain Emergency Medicine (ICAR MEDCOM). High Alt Med Biol 2011;12:335-41.

78. Pietsch U, Lischke V, Pietsch C, Kopp KH. Mechanical chest compressions in an avalanche victim with cardiac arrest: an option for extreme mountain rescue operations. Wilderness Environ Med 2014;25:190-3.

79. Ellerton J, Gilbert H. Should helicopters have a hoist or 'Iong-line' capability to perform mountain rescue in the UK? Emerg Med J 2012;29: 56-9

80. Boyd J, Brugger $H$, Shuster M. Prognostic factors in avalanche resuscitation: a systematic review. Resuscitation 2010;81:645-52

81. Lightning-associated deaths - United States, 1980-1995. MMWR Morb Mortal Wkly Rep 1998;47:3914.

82. Zafren $K$, Durrer $B$, Herry JP, Brugger $H$. Lightning injuries: prevention and on-site treatment in mountains and remote areas. Official guidelines of the International Commission for Mountain Emergency Medicine and the
Medical Commissionofthe InternationalMountaineering and Climbing Federation (ICAR and UIAA MEDCOM). Resuscitation 2005;65:369-72.

83. Why asthma still kills: the national review of asthma deaths (NRAD). Confi- dential enquiry report 2014; 2014. From: http://www.rcplondon.ac.uk/sites/ default/files/ why-asthma-still-kills-full-report.pdf

84. Hubner P, Meron G, Kurkciyan I, et al. Neurologic causes of cardiac arrest and outcomes. J Emerg Med 2014;47:6607.

85. Skrifvars MB, Parr MJ. Incidence, predisposing factors, management and survival following cardiac arrest due to subarachnoid haemorrhage: a review of the literature. Scand J Trauma Resusc Emerg Med 2012;20: 75.

86. Arnaout M, Mongardon N, Deye N, et al. Out-of-hospital cardiac arrest from brain cause: epidemiology, clinical features, and outcome in a multicenter cohort. Crit Care Med 2015;43:453-60.

87. Adabag S, Huxley RR, Lopez FL, et al. Obesity related risk of sudden cardiac death in the atherosclerosis risk in communities study. Heart 2015;101:215-21.

88. Lipman S, Cohen S, Einav S, et al. The Society for Obstetric Anesthesia and Perinatology consensus statement on the management of cardiac arrest in pregnancy. Anesth Analg 2014;118:1003-16

89. Boyd R, Teece S. Towards evidence based emergency medicine: best BETs from the Manchester Royal Infirmary. Perimortem caesarean section. Emerg Med J 2002; 19:324-5.

90. Nolan JP, Neumar RW,Adrie C, et al. Post-cardiac arrest syndrome: epidemiology, pathophysiology, treatment, and prognostication. A Scientific Statement from the International Liaison Committee on Resuscitation; the American Heart Association Emergency Cardiovascular Care Committee; the Council on Cardiovascular Surgery and Anesthesia; the Council on Cardiopulmonary, Perioperative, and Critical Care; the Council on Clinical Cardiology; the Council on Stroke. Resuscitation 2008;79:350-79.

91. Soholm H, Wachtell K, Nielsen SL, et al. Tertiary centres have improved survival compared to other hospitals in the Copenhagen area after out-ofhospital cardiac arrest. Resuscitation 2013;84:162-7.

92. Morimoto Y, Kemmotsu O, Kitami K, Matsubara I, Tedo I. Acute brain swelling after out-of-hospital cardiac arrest: pathogenesis and outcome. Crit Care Med 1993;21:10410.

93. Sakabe T, Tateishi A, Miyauchi Y, et al. Intracranial pressure following cardiopulmonary resuscitation. Intensive Care Med 1987;13:256-9.

94. Camuglia AC, Randhawa VK, Lavi S, Walters DL. Cardiac catheterization is associated with superior outcomes for survivors of out of hospital cardiac arrest: review and meta-analysis. Resuscitation 2014;85:1533-40.

95. Grasner JT, Meybohm P, Caliebe A, et al. Postresuscitation care with mild therapeutic hypothermia and coronary intervention after out-of-hospital cardiopulmonary resuscitation: a prospective registry analysis. Crit Care 2011;15:R61.

96. Takino M, Okada Y. Hyperthermia following cardiopulmonary resuscitation. Intensive Care Med 1991;17:419-20.

97. Takasu A, Saitoh D, Kaneko N, Sakamoto T, Okada Y. Hyperthermia: is it an ominous sign after cardiac arrest? Resuscitation 2001;49:273-7 
98. Zeiner A, Holzer M, Sterz F, et al. Hyperthermia after cardiac arrest is associated with an unfavorable neurologic outcome. Arch Intern Med 2001;161:2007-12.

99. Spaite DW, Bobrow BJ, Stolz U, et al. Statewide regionalization of postarrest care for out-of-hospital cardiac arrest: association with survival and neurologic outcome. Ann E Fischer M, Bottiger BW, Popov-Cenic S, Hossmann $K A$. Thrombolysis using plasminogen activator and heparin reduces cerebral no-reflow after resuscitation from cardiac arrest: an experimental study in the cat. Intensive Care Med 1996;22:1214-23.merg Med 2014;64:496-506, e1.

100. Cronberg T, Lilja G, Horn J, et al. Neurologic function and health-related quality of life in patients following targeted temperature management at 33 degrees C vs 36 degrees C after out-of-hospital cardiac arrest: a randomized clinical trial. JAMA Neurol 2015

101. Moulaert VRMP, Verbunt JA, van Heugten CM, Wade DT. Cognitive impairments in survivors of out-of-hospital cardiac arrest: a systematic review. Resuscitation 2009;80:297-305.

102. Cronberg $T$, Lilja $G$, Rundgren $M$, Friberg $H$, Widner $H$. Long-term neurological outcome after cardiac arrest and therapeutic hypothermia. Resuscitation 2009;80:111923.

103. Torgersen J, Strand K, Bjelland TW, et al. Cognitive dysfunction and healthrelated quality of life after a cardiac arrest and therapeutic hypothermia. Acta Anaesthesiol Scand 2010;54:721-8

104. Cobbe SM, Dalziel K, Ford I, Marsden AK. Survival of 1476 patients initially resuscitated from out of hospital cardiac arrest. BMJ 1996;312:1633-7.

105. Marsch S, Tschan F, Semmer NK, Zobrist R, Hunziker PR, Hunziker S. ABC versus CAB for cardiopulmonary resuscitation: a prospective, randomized simulator-based trial. Swiss Med Wkly 2013;143:w13856.

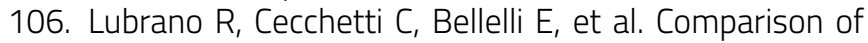
times of intervention during pediatric CPR maneuvers using $A B C$ and $C A B$ sequences: a randomized trial. Resuscitation 2012;83:1473-7.

107. Sekiguchi $H$, Kondo $Y$, Kukita I. Verification of changes in the time taken to initiate chest compressions according to modified basic life support guidelines. Am J Emerg Med 2013;31:1248-50

108. Kitamura T, Iwami T, Kawamura T, et al. Conventional and chestcompression-only cardiopulmonary resuscitation by bystanders for children who have out-of-hospital cardiac arrests: a prospective, nationwide, population-based cohort study. . Marsch S, Tschan F, Semmer NK, Zobrist R, Hunziker PR, Hunziker S. ABC versus $\mathrm{CAB}$ for cardiopulmonary resuscitation: a prospective, randomized simulator-based trial. Swiss Med Wkly 2013;143:w13856. Lancet 2010;375:1347-54.

109. Goto Y, Maeda T, Goto Y. Impact of dispatcher-assisted bystander cardiopulmonary resuscitation on neurological outcomes in children with out-of-hospital cardiac arrests: a prospective, nationwide, population-based cohort study. J Am Heart Assoc 2014;3:e000499.

110. Sutton RM, French B, Niles DE, et al. 2010 American Heart Association recommended compression depths during pediatric in-hospital resuscitations are associated with survival. Resuscitation 2014;85:1179-84.

111. Maconochie I, de Caen A, Aickin R, et al. Part 6: pedia- tric basic life support and pediatric advanced life support. 2015 International Consensus on Cardiopulmonary Resuscitation and Emergency Cardiovascular Care Science With Treatment Recommendations. Resuscitation 2015

112. Maitland K, Kiguli S, Opoka RO, et al. Mortality after fluid bolus in African children with severe infection. N Engl J Med 2011;364:2483-95

113. Maitland K, George EC, Evans JA, et al. Exploring mechanisms of excess mortality with early fluid resuscitation: insights from the FEAST trial. BMC Med 2013;11:68

114. Kelm DJ, Perrin JT, Cartin-Ceba R, Gajic O, Schenck L, Kennedy CC. Fluid overload in patients with severe sepsis and septic shock treated with early goal-directed therapy is associated with increased acute need for fluid-related medical interventions and hospital death. Shock 2015;43: $68-73$.

115. Gurnett CA, Atkins DL. Successful use of a biphasic waveform automated external defibrillator in a high-risk child. Am J Cardiol 2000;86:1051-3.

116. Rossano J, Quan L, Schiff MMAKDLA. Survival is not correlated with defibrillation dosing in pediatric out-of-hospital ventricular fibrillation. Circulation 2003;108. IV-320-1.

117. Samson R, Berg R, Bingham R. Pediatric Advanced Life Support Task Force ILCoR. Use of automated external defibrillators for children: an update. An advisory statement from the Pediatric Advanced Life Support Task Force, International Liaison Committee on Resuscitation. Resuscitation 2003;57:237-43.

118. Berg RA, Samson RA, Berg MD, et al. Better outcome after pediatric defibrillation dosage than adult dosage in a swine model of pediatric ventricular fibrillation. J Am Coll Cardiol 2005;45:786-9.

119. 2. Maconochie I, de Caen A, Aickin R, et al. Part 6: pediatric basic life support and pediatric advanced life support. 2015 International Consensus on Cardiopulmonary Resuscitation and Emergency Cardiovascular Care Science With Treatment Recommendations.Resuscitation 2015.

120. Gluckman PD, Wyatt JS, Azzopardi D, et al. Selective head cooling with mild systemic hypothermia after neonatal encephalopathy: multicentre randomised trial. Lancet 2005;365:663-70.

121. Moler FW, Silverstein FS, Holubkov R, et al. Therapeutic hypothermia after out-of-hospital cardiac arrest in children. N Engl J Med 2015;372: 1898-908.

122. Ghavam S, Batra D, Mercer J, et al. Effects of placentaltransfusion in extremely low birthweight infants: meta-analysis of long- and short-term outcomes. Transfusion 2014;54:1192-8.

123. Budin P [MaloneyWJ, Trans.] The nursling.The feeding and hygiene of premature and full-term infants. London: The Caxton Publishing Company; 1907

124. Wyllie J, Perlman JM, Kattwinkel J, et al. Part 7: Neonatal resuscitation: 2015 International Consensus on Cardiopulmonary Resuscitation and Emergency Cardiovascular Care Science With Treatment Recommendations. Resuscitation 2015.

125. Owen CJ, Wyllie JP. Determination of heart rate in the baby at birth. Resuscitation 2004;60:213-7.

126. Kamlin CO, O'Donnell CP, Everest NJ, Davis PG, Morley CJ.Accuracy of clinical assessment of infant heart rate in 
the delivery room. Resuscitation 2006;71:319-21.

127. Voogdt KG, Morrison AC, Wood FE, van Elburg RM, Wyllie JP. A randomised, simulated study assessing auscultation of heart rate at birth. Resuscitation 2010;81:1000-3.

128. Al Takroni AM, Parvathi CK, Mendis KB, Hassan S, Reddy I, Kudair HA. Selective tracheal suctioning to prevent meconium aspiration syndrome. Gynaecol Obstet 1998;63:259-63.

129. Chettri S, Adhisivam B, Bhat BV. Endotracheal suction for nonvigorous neonates born through meconium stained amniotic fluid: a randomized controlled trial. J Pediatr 2015.

130. Davis RO, Philips III JB, Harris Jr BA, Wilson ER, Huddleston JF. Fatal meconium aspiration syndrome occurring despite airway management considered appropriate. Am J Obstet Gynecol 1985;151:731-6.

131. Wyllie J, Perlman JM, Kattwinkel J, et al. Part 11: Neonatal resuscitation: 2010 International Consensus on Cardiopulmonary Resuscitation and Emergency Cardiovascular Care Science with Treatment Recommendations. Resuscitation 2010;81(Suppl. 1):e260-87

132. Vyas $H$, Milner AD, Hopkin IE, Boon AW. Physiologic responses to prolonged andslow-rise inflationinthe resuscitationofthe asphyxiatednewborninfant. J Pediatr 1981;99:635-9

133. Boon AW, Milner AD, Hopkin IE.Lung expansion, tidal exchange, and formation of the functional residual capacity during resuscitation of asphyxiated neonates. J Pediatr 1979;95:1031-6

134. Dawson JA, Schmolzer GM, Kamlin CO, et al. Oxygenation with T-piece versus self-inflating bag for ventilation of extremely preterm infants at birth: a randomized controIled trial. J Pediatr 2011;158:912-8, e1-2.

135. Szyld E, Aguilar A, Musante GA, et al. Comparison of devices for newborn ventilation in the delivery room. J Pediatr 2014;165, 234-9.e3.

136. Hartung JC, Schmolzer G, Schmalisch G, Roehr CC. Repeated thermosterilisation further affects the reliability of positive end-expiratory pressure valves. J Paediatr Child Health 2013:49:741-5

137. American College of Emergency P, Society for Cardiovascular A, Interventions, et al. 2013 ACCF/AHA guideline for the management of ST-elevation myocardial infarction: a report of the American College of Cardiology Foundation/American Heart Association Task Force on Practice Guidelines. J Am Coll Cardiol 2013;61:e78-140.

138. Amsterdam EA,Wenger NK, Brindis RG, et al. 2014 AHA/ACC Guideline for the Management of Patients with Non-ST-Elevation Acute Coronary Syndromes: a report of the American College of Cardiology/American Heart Association Task Force on Practice Guidelines. J Am Coll Cardiol 2014;64:e139-228

139. Canto JG, Rogers WJ, Bowlby LJ, French WJ, Pearce DJ, Weaver WD. The prehospital electrocardiogram in acute myocardial infarction: is its full potential being realized? National Registry of Myocardial Infarction 2 Investigators. J Am Coll Cardiol 1997;29:498-505

140. Terkelsen CJ, Lassen JF, Norgaard BL, et al. Reduction of treatment delay in patients with ST-elevation myocardial infarction: impact of pre-hospital diagnosis and direct referral to primary percutanous coronary intervention. Eur Heart J 2005;26:770-7.
141. Carstensen S, Nelson GC, Hansen PS, et al. Field triage to primary angioplasty combined with emergency department bypass reduces treatment delays and is associated with improved outcome. Eur Heart J 2007;28: 2313-9

142. Brown JP, Mahmud E, Dunford JV, Ben-Yehuda O. Effect of prehospital 12-lead electrocardiogram on activation ofthe cardiac catheterization laboratory and door-to-balloon time in ST-segment elevation acute myocardial infarction. Am J Cardiol 2008;101:158-61.

143. Keller T, Zeller T, Peetz D, et al. Sensitive troponin I assay in early diagnosis of acute myocardial infarction. $\mathrm{N}$ Engl J Med 2009;361:868-77.

144. Mega JL, Braunwald E, Wiviott SD, et al. Rivaroxaban in patients with a recent acute coronary syndrome. N Engl J Med 2012;366:9-19

145. Nikolaou NI, Arntz HR, Bellou A, Beygui F, Bossaert LL, Cariou A. European Resuscitation Council Guidelines for Resuscitation 2015 Section 8. Initial management of acute coronary syndromes.Resuscitation 2015, http:// dx.doi.org/10.1016/j.resuscitation.2015.07.030.

146. Stub D, Smith K, Bernard S, et al. Air versus oxygen in ST-segment elevation myocardial infarction. Circulation 2015.

147. Rawles JM, Kenmure AC. Controlled trial of oxygen in uncomplicated myocardial infarction. $\mathrm{Br}$ Med J 1976;1:1121-3

148. Cabello JB, Burls A, Emparanza Jl, Bayliss S, Quinn T. Oxygen therapy for acute myocardial infarction. Cochrane Database Syst Rev 2013;8:CD007160.

149. Bradley EH, Herrin J,Wang Y, et al. Strategies for reducing the door-to-balloon time in acute myocardial infarction. $\mathrm{N}$ Engl J Med 2006;355:2308-20.

150. Nikolaou N, Welsford M, Beygui F, et al. Part 5: Acute coronary syndromes: 2015 International Consensus on Cardiopulmonary Resuscitation and Emergency Cardiovascular Care Science With Treatment Recommendations. Resuscitation 2015

151. Bonnefoy E, Lapostolle F, Leizorovicz A, et al. Primary angioplasty versus prehospital fibrinolysis in acute myocardial infarction: a randomised study. Lancet 2002;360:825-9.

152. Thiele H, Eitel I, Meinberg C, et al. Randomized comparison of pre-hospitalinitiated facilitated percutaneous coronary intervention versus primary percutaneous coronary intervention in acute myocardial infarction very early after symptom onset: the LIPSIA-STEMI trial (Leipzig immediate prehospital facilitated angioplasty in ST-segment myocardial infarction). JACC CardiovasC Interv 2011:4:605-14.

153. Keeley EC, Boura JA, Grines CL. Primary angioplasty versus intravenous thrombolytic therapy for acute myocardial infarction: a quantitative review of 23 randomised trials. Lancet 2003;361:13-20

154. Pinto DS, Kirtane AJ, Nallamothu BK, et al. Hospital delays in reperfusion for ST-elevation myocardial infarction: implications when selecting a reperfusion strategy. Circulation 2006;114:2019-25.

155. Nikolaou N, Welsford M, Beygui F, et al. Part 5: Acute coronary syndromes: 2015 International Consensus on Cardiopulmonary Resuscitation and Emergency Cardiovascular Care Science With Treatment Recommendations. Resuscitation 2015. 
156. Itoh T, Fukami $K$, Suzuki T, et al. Comparison of long-term prognostic evaluation between pre-intervention thrombolysis and primary coronary intervention: a prospective randomized trial: five-year results of the IMPORTANT study. Circ J 2010;74:1625-34.

157. Kurihara H, Matsumoto S, Tamura R, et al. Clinical outcome of percutaneous coronary intervention with antecedent mutant t-PA administration for acute myocardial infarction. Am Heart J 2004;147:E14.

158. Rab T, Kern KB, Tamis-Holland JE, et al. Cardiac arrest: a treatment algorithm for emergent invasive cardiac procedures in the resuscitated comatose patient. J Am Coll Cardiol 2015;66:62-73

159. Wall HK, Beagan BM, O'Neill J, Foell KM, Boddie-Willis $\mathrm{CL}$. Addressing stroke signs and symptoms through public education: the Stroke Heroes Act FAST campaign. Prev Chronic Dis 2008;5:A49

160. Cason CL, Kardong-Edgren $S$, Cazzell M, Behan $D$, Mancini ME. Innovations in basic life support education for healthcare providers: improving competence in cardiopulmonary resuscitation through self-directed learning. J Nurses Staff Dev 2009;25:E1-13

161. Einspruch $E L$, Lynch $B$, Aufderheide TP, Nichol $G$, Becker L. Retention of CPR skills learned in a traditional AHA Heartsaver course versus 30-min video self-training: a controlled randomized study. Resuscitation 2007;74:476-86

162. Lynch B, Einspruch EL, Nichol G, Becker LB, Aufderheide TP, Idris A. Effectiveness of a 30-min CPR self-instruction program for lay responders: a controlled randomized study. Resuscitation 2005;67:31-43.

163. Chung CH, Siu AY, Po LL, Lam CY, Wong PC. Comparing the effectiveness of video self-instruction versus traditional classroom instruction targeted at cardiopulmonary resuscitation skills for laypersons: a prospective randomised controlled trial. Xianggang yi xue za zhi/Hong Kong Acad Med 2010;16:165-70.

164. Andreatta P, Saxton E, Thompson M, Annich G. Simulation-based mock codes significantly correlate with improved pediatric patient cardiopulmonary arrest survival rates. Pediatr Crit Care Med 2011;12:33-8.

165. Neily J, Mills PD, Young-Xu Y, et al. Association between implementation of a medical team training program and surgical mortality. JAMA 2010;304:1693-700.

166. Song KJ, Shin SD, Park CB, et al. Dispatcher-assisted bystander cardiopulmonary resuscitation in a metropolitan city: a before-after population-based study. Resuscitation 2014;85:34-41

167. Soreide $E$, Morrison L, Hillman $K$, et al. The formula for survival in resuscitation. Resuscitation 2013;84:148793.

168. Kudenchuk PJ, Redshaw JD, Stubbs BA, et al. Impact of changes in resuscitation practice on survival and neurological outcome after out-ofhospital cardiac arrest resulting from nonshockable arrhythmias. Circulation 2012;125:1787-94

169. Hillman $K$, Chen J, Cretikos $M$, et al. Introduction of the medical emergency team (MET) system: a cluster-randomised controlled trial. Lancet 2005;365:2091-7

170. Roppolo LP, Pepe PE, Campbell L, et al. Prospective, randomized trial of the effectiveness and retention of 30-min layperson training for cardiopulmonary resusci- tation and automated external defibrillators: The American Airlines Study. Resuscitation 2007;74:276-85.

171. Woollard M, Whitfeild $R$, Smith $A$, et al. Skill acquisition and retention in automated external defibrillator (AED) use and CPR by lay responders: a prospective study. Resuscitation 2004;60:17-28

172. Kaldjian LC, Weir RF, Duffy TP. A clinician's approach to clinical ethical reasoning. J Gen Intern Med 2005;20:30611.

173. O'Neill O. Autonomy and trust in bioethics. Cambridge/ New York: Cambridge University Press; 2002.

174. Beauchamp TL, Childress JF. Principles of biomedical ethics.6th ed. New York: Oxford University Press; 2009.

175. World Medical Association.Medical ethics manual.2nd ed. World Medical Association; 2009.

176. Lippert FK, Raffay V, Georgiou M, Steen PA, Bossaert L. European Resuscitation Council Guidelines for Resuscitation 2010 Section 10. The ethics of resuscitation and end-of-life decisions. Resuscitation 2010;81: 1445-51.

177. Morrison LJ, Kierzek G, Diekema DS, et al. Part 3: ethics: 2010 American Heart Association Guidelines for Cardiopulmonary Resuscitation and Emergency Cardiovascular Care. Circulation 2010;122:S665-75.

178. 4. Xanthos T. 'Do not attempt cardiopulmonary resuscitation' or 'allowing natural death'? The time for resuscitation community to review its boundaries and its terminology. Resuscitation 2014;85:1644-5

179. Salkic $A$, Zwick A. Acronyms of dying versus patient autonomy. Eur J Health Law 2012;19:289-303. 